\title{
Eficiência de métodos de amostragem de lagartas e de percevejos na cultura de soja
}

\author{
Efficiency of sampling methods for caterpillars and stink bugs in soybean
}

\author{
Glauber Renato Stürmer ${ }^{\text {I }}$ Alberto Cargnelutti FilhoII Lucas da Silva Stefanelo III \\ Jerson Vanderlei Carús Guedes ${ }^{\mathrm{IV}}$
}

RESUMO

$O$ objetivo deste trabalho foi comparar a capacidade de coleta de três métodos de amostragem de lagartas e de percevejos na cultura de soja. Para isso, em área de 6,16ha de soja, foi demarcado um gride de 154 pontos amostrais, espaçados de $20 \times 20 \mathrm{~m}$. Em cada um desses 154 pontos, foram coletadas lagartas (pequenas, grandes e total) e percevejos (ninfas, adultos e total) (seis variáveis), por meio dos métodos de amostragem pano-de-batida, pano-de-batida largo e panode-batida vertical, em 14 estádios fenológicos da cultura de soja, totalizando 6.468 coletas. Para cada uma dessas seis variáveis, em cada um dos 14 estádios fenológicos e no geral (todos os estádios fenológicos), as médias dos três métodos de amostragem foram comparadas pelo teste $t$ (bilateral) de Student para dados pareados, em nível de $5 \%$ de probabilidade. $O$ número de lagartas coletadas por meio dos métodos de amostragem é decrescente na seguinte ordem: pano-de-batida vertical, pano-de-batida largo e pano-de-batida. $O$ número de percevejos coletados por meio dos métodos de amostragem pano-de-batida vertical e pano-de-batida largo é superior ao pano-de-batida. O pano-de-batida vertical é o mais eficiente para a coleta de lagartas e de percevejos.

Palavras-chave: pano-de-batida, monitoramento, Noctuidae, Pentatomidae, MIP.

\section{ABSTRACT}

The aim of this study was to compare the collect capacity of three sampling methods for caterpillars and stink bugs in soybean. Therefore, in a 6.16ha soybean field, a grid of 154 sampling points spaced $20 \times 20 \mathrm{~m}$ was marked. In each of these 154 points were collected caterpillars (small, large and total) and stink bugs (nymphs, adults and total) (six variables) by the sampling methods beating cloth, wide beating cloth and vertical beat sheet, on 14 phenological stages of the soybean crop, totaling 6,468 samples. For each of these six variables, on each of the 14 phenological stages and overall (all phenological stages), the averages of the three sampling methods were compared by Student's $t$ test (bilateral) for paired data, in a $5 \%$ probability level. The number of caterpillars collected by the sampling methods decreases in the following order: vertical beat sheet, wide beating cloth and beating cloth. The number of stink bugs collected by the sampling methods vertical beat sheet and wide beating cloth is higher than beating cloth. Vertical beat sheet is the most efficient to collect caterpillars and stink bugs.

Key words: beating cloth, scouting, Noctuidae, Pentatomidae, IPM.

\section{INTRODUÇÃO}

Entre os principais fatores limitantes da produtividade de grãos da cultura de soja estão os problemas fitossanitários, como a presença de espécies de lagartas (Anticarsia gemmatalis, Pseudoplusia includens e Spodoptera eridania) e de percevejos (Piezodorus guildinii, Nezara viridula, Euschistus heros, Dichelops furcatus, Edessa meditabunda e Chinavia sp.). As lagartas alimentam-se do limbo e das nervuras foliares, ocasionando desfolhamento de até $100 \%$, quando não manejadas, e redução na produtividade de grãos (LOURENÇÃO et al., 2010).

IPrograma de Pós-graduação em Agronomia, Universidade Federal de Santa Maria (UFSM), Santa Maria, RS, Brasil.

"Departamento de Fitotecnia, Centro de Ciências Rurais (CCR), UFSM, 97105-900, Santa Maria, RS, Brasil. E-mail: alberto.cargnelutti.filho@gmail.com. Autor para correspondência.

${ }^{\mathrm{II}}$ Curso de Agronomia, UFSM, Santa Maria, RS, Brasil.

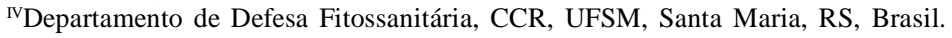


Ao se alimentarem dos grãos, os percevejos causam atrofiamento, diminuição do peso e da qualidade desses (CORRÊA-FERREIRA\&AZEVEDO, 2002; BELORTE et al., 2003).

É importante quantificar a densidade populacional de lagartas e de percevejos, para que, com base nos níveis de controle estabelecidos, sejam tomadas decisões adequadas sobre o seu manejo. Na soja, o nível de controle recomendado é de 20 lagartas grandes por metro de fileira, ou $30 \%$ de desfolha no período vegetativo, ou $15 \%$ de desfolha no período reprodutivo. Para percevejos, o nível de controle recomendado é dois e um percevejos por metro linear, para lavouras de produção de grãos ou sementes, respectivamente (REUNIÃO DE PESQUISADESOJADA REGIÃOSUL, 2010).

Existem diversos métodos para amostragem e quantificação de insetos-praga. A escolha do método de amostragem é dependente da cultura, do estádio fenológico, das espécies-alvo, da precisão e exatidão requerida, da facilidade de uso, do tempo e do custo desses métodos (WADE et al., 2006). Métodos de amostragem como o pano-de-batida (BOYER \& DUMAS, 1969), o pano-de-batida largo (CORREAFERREIRA\& PAVÃO, 2005) e o pano-de-batida vertical (DREES \& RICE, 1985) são utilizados para amostragem de insetos-praga na cultura de soja.

Estudos comparativos entre métodos de amostragem para a coleta de insetos-praga nas culturas de soja (SHEPARD et al., 1974; COSTA \& CORSEUIL, 1979; SANE et al., 1999; MASSARO \& GAMUNDI, 2003; CORRÊA-FERREIRA \& PAVÃO, 2005; GUEDES et al., 2006), de algodoeiro (DEGRANDE et al., 2003; WADE et al., 2006; MUSSER et al., 2007; KNUTSON et al., 2008) e de café (LARA et al., 2008) têm sido realizados. De maneira geral, esses trabalhos evidenciaram que as quantidades de insetos-praga coletadas por meio dos métodos são variáveis. Na prática, é importante utilizar o método de amostragem relativo que colete o maior número de insetos-praga, ou seja, o mais próximo possível da densidade populacional real, que seria mensurada somente por método de amostragem absoluto (SANE et al., 1999). Na cultura de soja, alguns métodos de amostragem carecem de estudos comparativos sobre a sua capacidade de coleta. Assim, o objetivo deste trabalho foi comparar a capacidade de coleta de três métodos de amostragem de lagartas e de percevejos na cultura de soja.

\section{MATERIAL E MÉTODOS}

O experimento foi conduzido em área de 6,16ha de soja, localizada a 2942'24'S, 5348'42'W, e a 95m de altitude. A cultivar de soja 'BMX Potência RR' foi semeada no dia 29 de outubro de 2010, em linhas espaçadas a $0,5 \mathrm{~m}$, com densidade de 25 plantas $\mathrm{m}^{-2}$. A adubação e o controle de plantas daninhas e de doenças foram realizados de acordo com as recomendações técnicas para a cultura (REUNIÃO DE PESQUISA DE SOJA DA REGIÃO SUL, 2010). Foi realizada uma aplicação de metomil (107g i.a. ha ${ }^{-1}$ ) para o controle de lagartas no dia 03 de fevereiro de 2011, em função da desfolha ter atingido o nível de controle. Para os percevejos, não foi realizado controle, pois o nível de controle foi atingido somente no estádio fenológico R7.1.

Sobre a cultura foi demarcado um gride de 154 pontos amostrais, espaçados de $20 \times 20 \mathrm{~m}$. Em cada um desses 154 pontos, foram coletadas lagartas e percevejos, por meio dos métodos de amostragem panode-batida (Figura 1A), pano-de-batida largo (Figura 1B) e pano-de-batida vertical (Figura 1C), em 14 estádios fenológicos da cultura de soja (V7, V9, V11, R1, R2, R3, R4, R5.1, R5.3, R5.5, R6, R7.1, R7.3 e R8.2) (RITCHIE et al., 1982). Os três métodos de amostragem avaliados e as respectivas formas de coleta são descritos a seguir.

Pano-de-batida: constituído de dois bastões de madeira ligados entre si por um tecido branco, com comprimento de $1 \mathrm{~m}$ e largura de $0,5 \mathrm{~m}$, ajustável ao espaçamento entre linhas. Para a coleta dos insetospraga, o pano foi desenrolado sobre o solo, entre as fileiras de soja. Posteriormente, as plantas das duas fileiras (área $=1 \mathrm{~m}^{2}$ ) foram sacudidas, vigorosamente, a fim de derrubar os insetos-praga sobre o pano.

Pano-de-batida largo: constituído de dois bastões de madeira ligados entre si por um tecido branco, com comprimento de $1 \mathrm{~m}$ e largura de $1,4 \mathrm{~m}$ (grande o suficiente para cobrir a linha de soja adjacente à amostrada). Para as coletas, uma extremidade do pano foi colocada entre as fileiras de soja, sendo ajustada à base das plantas de uma linha e a outra estendida sobre as plantas da linha adjacente. As plantas de uma fileira (área $=0,5 \mathrm{~m}^{2}$ ) foram sacudidas, vigorosamente, a fim de derrubar os insetos-praga sobre o pano. Esse procedimento foi realizado em dois metros de linha de soja, a fim de amostrar $1 \mathrm{~m}^{2}$ de área.

Pano-de-batida vertical: constituído de um bastão de madeira, na extremidade superior, e de um tubo de policloreto de polivinila $(100 \mathrm{~mm})$, cortado ao meio longitudinalmente, na extremidade inferior, ligados entre si por um tecido branco, com comprimento de $1 \mathrm{~m}$ e com altura ajustável à estatura das plantas de soja (semelhantemente ao pano-de-batida largo descrito anteriormente). $\mathrm{O}$ tubo de policloreto de polivinila serviu de calha coletora dos insetos-praga. Para a coleta dos insetos, o pano foi colocado verticalmente na entre linha da cultura, e as plantas de apenas uma fileira foram sacudidas contra a superfície do pano. Esse 


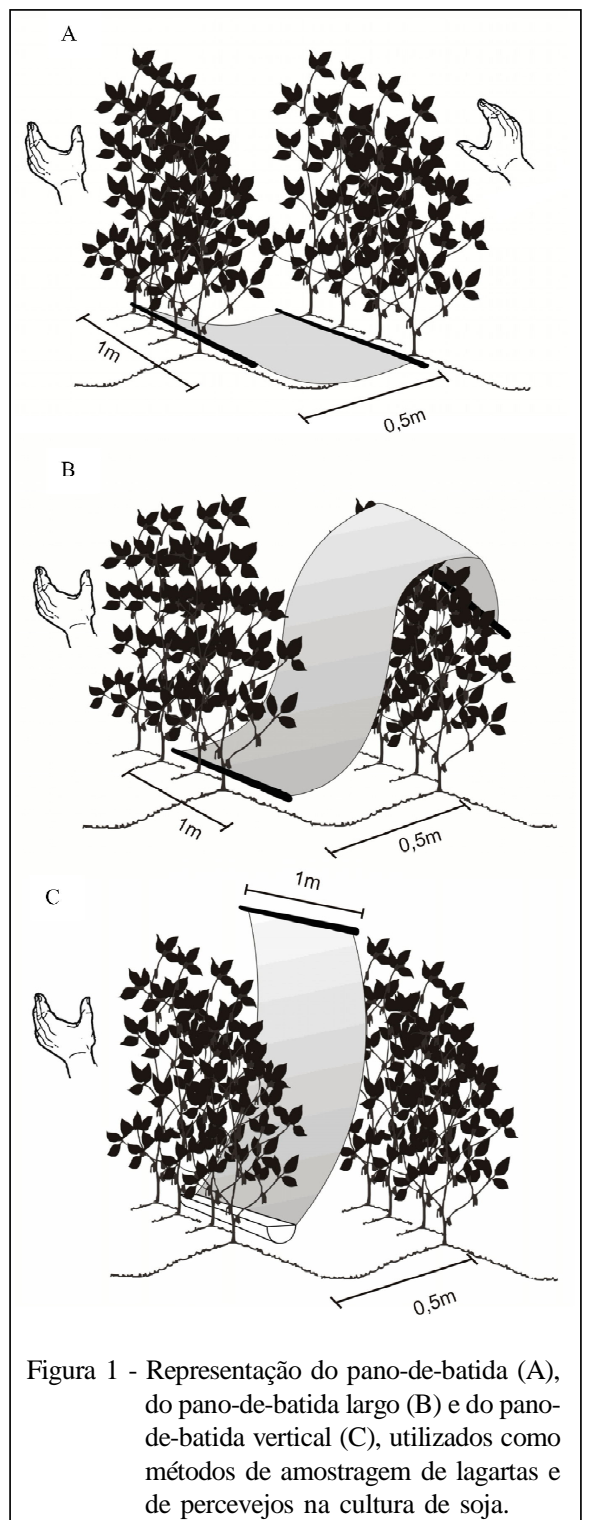

procedimento foi realizado em dois metros de linha de soja, a fim de amostrar $1 \mathrm{~m}^{2}$ de área.

Em cada uma das 6.468 coletas, de $1 \mathrm{~m}^{2}$ de área, formadas pela combinação de três métodos de amostragem $\times 154$ pontos $\times 14$ estádios fenológicos, foi contado o número de lagartas pequenas $(\leq 1,5 \mathrm{~cm})$, grandes $(>1,5 \mathrm{~cm})$ e o total (pequenas + grandes), independentemente das seguintes espécies que foram encontradas: A. gemmatalis, P. includens e S. eridania . Também foi contado o número de percevejos ninfas, adultos e total (ninfas + adultos), independentemente das seguintes espécies que foram encontradas: $\boldsymbol{D}$. furcatus, P. guildinii, E. meditabunda, N. viridula, $E$. heros e Chinavia sp..
Após, para cada uma dessas seis variáveis, em cada um dos 14 estádios fenológicos e no geral (total de todos os estádios fenológicos), as médias dos três métodos de amostragem foram comparadas pelo teste t (bilateral) de Student para dados pareados, em nível de 5\% de probabilidade. As análises estatísticas foram realizadas com o auxílio do programa GENES (CRUZ, 2006) e do aplicativo MS Office Excel 2007.

\section{RESULTADOS E DISCUSSÃO}

A densidade populacional de lagartas (média dos 154 pontos amostrais) oscilou entre 0,00 e 49,86 lagartas $\mathrm{m}^{-2}$ e a de percevejos variou entre $0,06 \mathrm{e}$ 
19,44 percevejos $\mathrm{m}^{-2}$ (Tabela 1). De maneira geral, em relação à média de lagartas (pequenas, grandes e total) e de percevejos (ninfas, adultos e total) coletadas nos 154 pontos, houve variabilidade entre os métodos de amostragem (pano-de-batida, pano-de-batida largo e pano-de-batida vertical) dentro dos estádios fenológicos e no geral (todos os estádios fenológicos). Essa variabilidade sugere que a capacidade de coleta de lagartas e de percevejos pode ser diferente entre os três métodos, e merece ser investigada para a identificação da eficiência dos métodos e sua recomendação na cultura da soja.

Em relação à densidade populacional, de maneira geral, nos estádios fenológicos V7 e V9, houve baixa incidência de lagartas $\left(\leq 1,02\right.$ lagartas $\left.\mathrm{m}^{-2}\right)$ (Tabela 1). A partir de V11, a densidade populacional foi crescente, até atingir o pico populacional em R4 (49,86 lagartas $\mathrm{m}^{-2}$ ). Após, houve decréscimo até R6, ocasionado, principalmente, pela aplicação de inseticida e pela competição entre as lagartas por alimento. A partir de R7.1, em nenhum dos três métodos de amostragem, foram coletadas lagartas. Já a densidade populacional de percevejos, de maneira geral, foi baixa $\left(\leq 0,46\right.$ percevejos $\left.\mathrm{m}^{-2}\right)$ até o estádio fenológico R2, devido, provavelmente ao ingresso tardio de percevejos e à cultura ainda não apresentar o alimento preferencial dos pentatomídeos (CORRÊAFERREIRA, 2005). Após, houve acréscimo da incidência até atingir o pico populacional em R7.3 (19,44 percevejos $\mathrm{m}^{-2}$ ) e posterior redução, a partir desse estádio fenológico. O período compreendido a partir do aparecimento dos legumes (R3) até os legumes com $100 \%$ de grãos cheios (R6) é considerado o período crítico para o ataque dos percevejos (CORRÊAFERREIRA\&AZEVEDO, 2002).

Nos estádios fenológicos com baixa incidência de lagartas $\left(\leq 1,02\right.$ lagartas $\left.\mathrm{m}^{-2}\right)$ e de percevejos $\left(\leq 0,46\right.$ percevejos $\left.\mathrm{m}^{-2}\right)$, a comparação dos três métodos de amostragem foi dificultada pela menor presença desses insetos (Tabela 1). Por outro lado, nos demais estádios fenológicos, a diferença entre os métodos pode ser comparada, de forma mais eficiente, pela maior densidade populacional. Portanto, diante das considerações realizadas, pode-se inferir que esse banco de dados oferece credibilidade ao estudo comparativo desses três métodos de amostragem.

De maneira geral, em relação ao número de lagartas pequenas coletadas por meio dos três métodos de amostragem, houve menor discriminação entre as médias dos métodos, nos estádios fenológicos iniciais (V7 e V9) e finais (R7.1, R7.3 e R8.2) (Tabela 1). Essa menor diferenciação entre os métodos está associada ao menor número de lagartas coletadas nesses estádios
( $\leq$ 0,83 lagartas $\left.\mathrm{m}^{-2}\right)$, o que dificulta a sua comparação. Entre os nove estádios fenológicos intermediários, em três deles (R3, R4 e R5.5), o número de lagartas pequenas coletadas não diferiu entre os métodos panode-batida vertical e pano-de-batida largo, porém, em ambos, o número de lagartas coletadas foi superior ao método pano-de-batida. Nos demais seis momentos (V11, R1, R2, R5.1, R5.3 e R6) e no geral (todos os estádios fenológicos), o número de lagartas pequenas, coletadas por meio dos métodos de amostragem, foi decrescente na seguinte ordem: pano-de-batida vertical, pano-de-batida largo e pano-de-batida. Embora em trabalho realizado por SHEPARD et al. (1974) não tenham sido comparados os três métodos de amostragem utilizados neste trabalho, os autores também verificaram que o pano-de-batida coletou menor número de lagartas pequenas, comparado aos métodos da rede de varredura e de D-Vac.

Em relação ao número de lagartas grandes coletadas por meio dos três métodos de amostragem, houve menor discriminação entre os métodos nos estádios fenológicos iniciais (V7, V9 e V11) e finais (R7.1, R7.3 e R8.2) (Tabela 1). Para os demais oito estádios fenológicos intermediários, em cinco (R1, R2, R3, R5.3 e R6), o número de lagartas grandes coletadas não diferiu entre os métodos pano-de-batida vertical e pano-de-batida largo e foi superior ao coletado com o pano-de-batida. Nos demais três momentos (R4, R5 e R5.5) e no geral (todos os estádios fenológicos), o número de lagartas grandes, coletadas por meio dos métodos de amostragem, foi decrescente na seguinte ordem: pano-de-batida vertical, pano-de-batida largo e pano-de-batida.

Em relação ao número de lagartas total (pequenas + grandes), de maneira geral, os resultados, como esperado, são semelhantes ao número de lagartas pequenas e grandes (Tabela 1). Portanto, quanto ao número de lagartas, coletadas por meio dos métodos de amostragem, pode-se inferir que foi decrescente na seguinte ordem: pano-de-batida vertical, pano-debatida largo e pano-de-batida. Resultado semelhante foi observado por GUEDES et al. (2006), que verificaram que o pano-de-batida vertical foi mais eficiente na coleta de $\boldsymbol{A}$. gemmatalis, em relação ao pano-de-batida. A maior eficiência de coleta do pano-de-batida vertical está relacionada à presença da superfície de batida entre as linhas de soja, impedindo que as lagartas desalojadas de uma linha prendam-se nas plantas da linha ao lado. Os autores salientam que, em avaliações realizadas em estádios fenológicos mais avançados da cultura, a área foliar também pode interferir na capacidade de coleta dos métodos. Por outro lado, a baixa capacidade de coleta do pano-de-batida pode ser explicada pela forma 
Tabela 1 - Média \pm desvio padrão do número de lagartas pequenas, grandes e total (pequenas + grandes) e de percevejos ninfas, adultos e total (ninfas + adultos) $\mathrm{m}^{-2}$, coletados em 154 pontos amostrais por meio dos métodos de amostragem pano-de-batida (PB), panode-batida largo (PBL) e pano-de-batida vertical (PBV) nos estádios fenológicos e no geral (todos os estádios fenológicos) da cultura de soja.

\begin{tabular}{|c|c|c|c|c|c|c|c|}
\hline \multirow{2}{*}{ Estádio $^{(1)}$} & \multirow{2}{*}{ Método } & \multicolumn{3}{|c|}{ 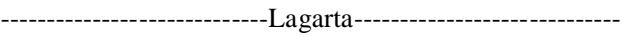 } & \multirow[b]{2}{*}{ Ninfa } & \multirow{2}{*}{$\begin{array}{l}\text { Adulto } \\
\text { Adrcevejo-- }\end{array}$} & \multirow[b]{2}{*}{ Total } \\
\hline & & Pequena & Grande & Total & & & \\
\hline V7 & PB & $0,38 \pm 0,70 a b$ & $0,04 \pm 0,19 b$ & $0,42 \pm 0,71 \mathrm{ab}$ & $0,01 \pm 0,08 \mathrm{a}$ & $0,05 \pm 0,22 b$ & $0,06 \pm 0,24 \mathrm{ab}$ \\
\hline V7 & PBL & $0,40 \pm 0,72 \mathrm{a}$ & $0,12 \pm 0,35 \mathrm{a}$ & $0,53 \pm 0,78 \mathrm{a}$ & $0,00 \pm 0,00 \mathrm{a}$ & $0,13 \pm 0,41 \mathrm{a}$ & $0,13 \pm 0,41 \mathrm{a}$ \\
\hline V7 & PBV & $0,25 \pm 0,59 b$ & $0,05 \pm 0,22 b$ & $0,31 \pm 0,63 b$ & $0,00 \pm 0,00 \mathrm{a}$ & $0,04 \pm 0,25 b$ & $0,04 \pm 0,25 b$ \\
\hline V9 & $\mathrm{PB}$ & $0,56 \pm 0,89 b$ & $0,21 \pm 0,45 \mathrm{a}$ & $0,77 \pm 1,00 b$ & $0,02 \pm 0,14 \mathrm{a}$ & $0,06 \pm 0,27 b$ & $0,08 \pm 0,30 \mathrm{a}$ \\
\hline V9 & PBL & $0,69 \pm 0,95 \mathrm{ab}$ & $0,19 \pm 0,50 \mathrm{a}$ & $0,89 \pm 1,06 a b$ & $0,01 \pm 0,11 \mathrm{a}$ & $0,11 \pm 0,41 \mathrm{ab}$ & $0,12 \pm 0,42 \mathrm{a}$ \\
\hline V9 & PBV & $0,83 \pm 1,20 \mathrm{a}$ & $0,19 \pm 0,45 \mathrm{a}$ & $1,02 \pm 1,34 \mathrm{a}$ & $0,02 \pm 0,14 \mathrm{a}$ & $0,14 \pm 0,36 \mathrm{a}$ & $0,16 \pm 0,40 \mathrm{a}$ \\
\hline V11 & $\mathrm{PB}$ & $1,20 \pm 1,28 \mathrm{c}$ & $0,71 \pm 1,07 b$ & $1,91 \pm 1,70 b$ & $0,01 \pm 0,08 \mathrm{a}$ & $0,06 \pm 0,24 \mathrm{a}$ & $0,06 \pm 0,25 \mathrm{a}$ \\
\hline V11 & PBL & $1,57 \pm 2,00 b$ & $0,61 \pm 0,87 b$ & $2,18 \pm 2,25 b$ & $0,04 \pm 0,19 a$ & $0,04 \pm 0,19 a$ & $0,08 \pm 0,31 \mathrm{a}$ \\
\hline V11 & $\mathrm{PBV}$ & $2,56 \pm 2,41 \mathrm{a}$ & $1,09 \pm 1,46 \mathrm{a}$ & $3,65 \pm 3,21 \mathrm{a}$ & $0,05 \pm 0,35 \mathrm{a}$ & $0,08 \pm 0,32 \mathrm{a}$ & $0,13 \pm 0,47 a$ \\
\hline $\mathrm{R} 1$ & $\mathrm{~PB}$ & $1,84 \pm 2,12 \mathrm{c}$ & $0,72 \pm 0,95 b$ & $2,56 \pm 2,38 \mathrm{c}$ & $0,05 \pm 0,24 \mathrm{a}$ & $0,03 \pm 0,16 \mathrm{c}$ & $0,07 \pm 0,30 b$ \\
\hline $\mathrm{R} 1$ & PBL & $3,77 \pm 2,80 b$ & $1,08 \pm 1,22 \mathrm{a}$ & $4,85 \pm 3,15 b$ & $0,09 \pm 0,39 a$ & $0,26 \pm 0,56 a$ & $0,35 \pm 0,68 \mathrm{a}$ \\
\hline $\mathrm{R} 1$ & PBV & $5,11 \pm 3,48 a$ & $1,08 \pm 1,29 a$ & $6,19 \pm 3,91 \mathrm{a}$ & $0,12 \pm 0,52 \mathrm{a}$ & $0,12 \pm 0,35 b$ & $0,24 \pm 0,63 \mathrm{a}$ \\
\hline $\mathrm{R} 2$ & $\mathrm{~PB}$ & $2,63 \pm 2,43 c$ & $2,01 \pm 1,60 b$ & $4,64 \pm 3,05 c$ & $0,12 \pm 0,47 \mathrm{~b}$ & $0,06 \pm 0,24 b$ & $0,18 \pm 0,51 b$ \\
\hline $\mathrm{R} 2$ & PBL & $5,55 \pm 4,65 b$ & $3,85 \pm 4,24 \mathrm{a}$ & $9,40 \pm 6,72 b$ & $0,21 \pm 0,64 \mathrm{ab}$ & $0,21 \pm 0,57 \mathrm{a}$ & $0,43 \pm 0,84 a$ \\
\hline $\mathrm{R} 2$ & PBV & $9,05 \pm 5,95 \mathrm{a}$ & $3,29 \pm 3,20 \mathrm{a}$ & $12,34 \pm 7,36 \mathrm{a}$ & $0,27 \pm 0,59 \mathrm{a}$ & $0,19 \pm 0,54 \mathrm{a}$ & $0,46 \pm 0,91 a$ \\
\hline R3 & PB & $9,88 \pm 4,25 b$ & $3,95 \pm 3,34 b$ & $13,83 \pm 5,09 \mathrm{c}$ & $0,10 \pm 0,36 b$ & $0,11 \pm 0,39 b$ & $0,21 \pm 0,53 b$ \\
\hline $\mathrm{R} 3$ & PBL & $25,51 \pm 12,36 a$ & $8,61 \pm 6,37 \mathrm{a}$ & $34,12 \pm 12,57 b$ & $0,52 \pm 0,98 \mathrm{a}$ & $0,24 \pm 0,51 \mathrm{a}$ & $0,76 \pm 1,18 \mathrm{a}$ \\
\hline $\mathrm{R} 3$ & PBV & $26,51 \pm 12,60 \mathrm{a}$ & $10,01 \pm 7,20 \mathrm{a}$ & $36,53 \pm 12,25 \mathrm{a}$ & $0,53 \pm 0,89 a$ & $0,34 \pm 0,68 \mathrm{a}$ & $0,87 \pm 1,20 \mathrm{a}$ \\
\hline $\mathrm{R} 4$ & PB & $11,29 \pm 6,79 b$ & $9,01 \pm 4,50 \mathrm{c}$ & $20,31 \pm 8,55 c$ & $0,25 \pm 0,58 b$ & $0,17 \pm 0,42 b$ & $0,42 \pm 0,71 b$ \\
\hline $\mathrm{R} 4$ & PBL & $24,45 \pm 14,34 \mathrm{a}$ & $19,16 \pm 9,71 b$ & $43,62 \pm 17,50 \mathrm{~b}$ & $0,48 \pm 0,94 a$ & $0,27 \pm 0,60 \mathrm{ab}$ & $0,75 \pm 1,18 \mathrm{a}$ \\
\hline $\mathrm{R} 4$ & PBV & $24,33 \pm 11,13 \mathrm{a}$ & $25,53 \pm 11,46 a$ & $49,86 \pm 19,38 \mathrm{a}$ & $0,53 \pm 0,92 \mathrm{a}$ & $0,34 \pm 0,70 \mathrm{a}$ & $0,86 \pm 1,24 a$ \\
\hline R5.1 & PB & $1,68 \pm 1,81 \mathrm{c}$ & $1,73 \pm 1,80 \mathrm{c}$ & $3,40 \pm 2,78 \mathrm{c}$ & $0,18 \pm 0,49 b$ & $0,18 \pm 0,43 b$ & $0,36 \pm 0,71 b$ \\
\hline R5.1 & PBL & $3,86 \pm 3,25 b$ & $3,93 \pm 2,98 b$ & $7,79 \pm 4,78 b$ & $0,66 \pm 1,09 a$ & $0,53 \pm 1,09 a$ & $1,19 \pm 1,54 a$ \\
\hline R5.1 & PBV & $4,52 \pm 3,30 \mathrm{a}$ & $4,54 \pm 3,27 \mathrm{a}$ & $9,06 \pm 5,30 \mathrm{a}$ & $0,69 \pm 1,07 \mathrm{a}$ & $0,47 \pm 0,86 a$ & $1,16 \pm 1,50 \mathrm{a}$ \\
\hline R5.3 & PB & $0,95 \pm 1,39 \mathrm{c}$ & $0,90 \pm 1,20 \mathrm{~b}$ & $1,84 \pm 1,90 \mathrm{c}$ & $0,24 \pm 0,57 b$ & $0,28 \pm 0,67 b$ & $0,52 \pm 1,01 b$ \\
\hline R5.3 & PBL & $1,57 \pm 2,03 b$ & $1,71 \pm 1,44 \mathrm{a}$ & $3,28 \pm 2,64 b$ & $0,39 \pm 0,70 a$ & $0,69 \pm 0,99 a$ & $1,08 \pm 1,34 \mathrm{a}$ \\
\hline R5.3 & PBV & $2,14 \pm 2,97 \mathrm{a}$ & $1,73 \pm 1,70 \mathrm{a}$ & $3,86 \pm 3,74 a$ & $0,47 \pm 0,83 a$ & $0,57 \pm 0,85 a$ & $1,04 \pm 1,23 \mathrm{a}$ \\
\hline R5.5 & PB & $0,68 \pm 1,06 b$ & $0,18 \pm 0,43 c$ & $0,86 \pm 1,25 b$ & $0,45 \pm 1,03 \mathrm{~b}$ & $0,21 \pm 0,47 b$ & $0,66 \pm 1,09 b$ \\
\hline R5.5 & PBL & $1,78 \pm 2,17 \mathrm{a}$ & $0,39 \pm 0,74 b$ & $2,17 \pm 2,45 \mathrm{a}$ & $1,03 \pm 3,59 \mathrm{ab}$ & $0,59 \pm 0,84 a$ & $1,62 \pm 3,64 a$ \\
\hline R5.5 & PBV & $1,44 \pm 1,82 \mathrm{a}$ & $0,59 \pm 0,97 a$ & $2,03 \pm 2,20 \mathrm{a}$ & $1,19 \pm 3,53 \mathrm{a}$ & $0,69 \pm 0,89 a$ & $1,88 \pm 3,58 \mathrm{a}$ \\
\hline R6 & PB & $0,14 \pm 0,38 \mathrm{c}$ & $0,03 \pm 0,16 b$ & $0,16 \pm 0,40 b$ & $1,15 \pm 1,66 \mathrm{c}$ & $0,27 \pm 0,56 b$ & $1,42 \pm 1,72 \mathrm{c}$ \\
\hline R6 & PBL & $0,27 \pm 0,62 b$ & $0,15 \pm 0,44 a$ & $0,42 \pm 0,81 \mathrm{a}$ & $2,76 \pm 3,16 b$ & $0,63 \pm 0,82 \mathrm{a}$ & $3,39 \pm 3,33 b$ \\
\hline R6 & PBV & $0,51 \pm 1,13 \mathrm{a}$ & $0,10 \pm 0,33 \mathrm{a}$ & $0,62 \pm 1,20 \mathrm{a}$ & $3,92 \pm 4,16 a$ & $0,69 \pm 0,94 a$ & $4,60 \pm 4,17 \mathrm{a}$ \\
\hline R7.1 & $\mathrm{PB}$ & $0,00 \pm 0,00 \mathrm{a}$ & $0,00 \pm 0,00 \mathrm{a}$ & $0,00 \pm 0,00 \mathrm{a}$ & $2,96 \pm 2,85 b$ & $0,60 \pm 0,87 b$ & $3,56 \pm 2,88 b$ \\
\hline R7.1 & PBL & $0,00 \pm 0,00 \mathrm{a}$ & $0,00 \pm 0,00 \mathrm{a}$ & $0,00 \pm 0,00 \mathrm{a}$ & $9,36 \pm 6,71 \mathrm{a}$ & $1,85 \pm 1,91 \mathrm{a}$ & $11,21 \pm 7,04 a$ \\
\hline R7.1 & PBV & $0,00 \pm 0,00 \mathrm{a}$ & $0,00 \pm 0,00 \mathrm{a}$ & $0,00 \pm 0,00 \mathrm{a}$ & $9,78 \pm 6,92 \mathrm{a}$ & $1,71 \pm 1,79 a$ & $11,49 \pm 7,41 \mathrm{a}$ \\
\hline R7.3 & PB & $0,00 \pm 0,00 \mathrm{a}$ & $0,00 \pm 0,00 \mathrm{a}$ & $0,00 \pm 0,00 \mathrm{a}$ & $4,46 \pm 3,53 b$ & $1,53 \pm 1,35 b$ & $5,99 \pm 3,91 b$ \\
\hline R7.3 & PBL & $0,00 \pm 0,00 \mathrm{a}$ & $0,00 \pm 0,00 \mathrm{a}$ & $0,00 \pm 0,00 \mathrm{a}$ & $14,09 \pm 7,65 \mathrm{a}$ & $5,34 \pm 3,63 a$ & $19,44 \pm 8,94 a$ \\
\hline R7.3 & PBV & $0,00 \pm 0,00 \mathrm{a}$ & $0,00 \pm 0,00 \mathrm{a}$ & $0,00 \pm 0,00 \mathrm{a}$ & $14,47 \pm 7,45 a$ & $4,88 \pm 3,68 \mathrm{a}$ & $19,34 \pm 8,42 \mathrm{a}$ \\
\hline $\mathrm{R} 8.2$ & PB & $0,00 \pm 0,00 \mathrm{a}$ & $0,00 \pm 0,00 \mathrm{a}$ & $0,00 \pm 0,00 \mathrm{a}$ & $4,01 \pm 3,45 b$ & $2,07 \pm 2,16 b$ & $6,08 \pm 4,34 b$ \\
\hline R8.2 & PBL & $0,00 \pm 0,00 \mathrm{a}$ & $0,00 \pm 0,00 \mathrm{a}$ & $0,00 \pm 0,00 \mathrm{a}$ & $9,97 \pm 6,16 \mathrm{a}$ & $5,49 \pm 3,49 a$ & $15,46 \pm 7,17 \mathrm{a}$ \\
\hline $\mathrm{R} 8.2$ & PBV & $0,00 \pm 0,00 \mathrm{a}$ & $0,00 \pm 0,00 \mathrm{a}$ & $0,00 \pm 0,00 \mathrm{a}$ & $10,05 \pm 5,57 \mathrm{a}$ & $5,01 \pm 3,07 \mathrm{a}$ & $15,06 \pm 6,68 \mathrm{a}$ \\
\hline Geral & PB & $2,23 \pm 4,27 \mathrm{c}$ & $1,39 \pm 2,92 \mathrm{c}$ & $3,62 \pm 6,54 \mathrm{c}$ & $1,00 \pm 2,23 b$ & $0,40 \pm 1,00 \mathrm{~b}$ & $1,40 \pm 2,81 b$ \\
\hline Geral & PBL & $4,96 \pm 9,94 b$ & $2,84 \pm 6,15 b$ & $7,80 \pm 14,56 b$ & $2,83 \pm 5,67 \mathrm{a}$ & $1,17 \pm a 2,37$ & $4,00 \pm 7,32 \mathrm{a}$ \\
\hline Geral & PBV & $5,52 \pm 9,90 \mathrm{a}$ & $3,44 \pm 7,72 \mathrm{a}$ & $8,96 \pm 16,16 \mathrm{a}$ & $3,01 \pm 5,76 \mathrm{a}$ & $1,09 \pm 2,20 \mathrm{a}$ & $4,10 \pm 7,25 \mathrm{a}$ \\
\hline
\end{tabular}

(1) Estádios fenológicos conforme escala de RITCHIE et al. (1982). Médias não seguidas de mesma letra diferem pelo teste t (bilateral) de Student para dados pareados, em nível de 5\% de probabilidade, com 153 graus de liberdade em cada estádio fenológico e 2.155 graus de liberdade no geral (todos os estádios fenológicos). 
que é realizada a amostragem, ou seja, após acondicionar o pano-de-batida na entrelinha da cultura, ambas as fileiras são agitadas para a queda das lagartas, com isso, ocorre um entrelaçamento das folhas e, assim, algumas lagartas não caem no pano de amostragem. Segundo DREES \& RICE (1985), fatores como o tempo de amostragem, a utilização em locais com a presença de ervas daninhas e restos culturais entre as fileiras dificultam a utilização do pano-de-batida e diminuem sua eficiência de coleta.

Comparações entre os métodos de coleta, com base nas amostragens realizadas até o estádio fenológico R2, são dificultadas pela menor densidade populacional de percevejos ( $\leq 0,46$ percevejos $\mathrm{m}^{-2}$ ) (Tabela 1). Assim, com base nos estádios fenológicos com maior densidade populacional de percevejos (R3, R4, R5.1, R5.3, R5.5, R6, R7.1, R7.3 e R8.2) e no geral (todos os estádios fenológicos), os resultados evidenciaram que os métodos de amostragem panode-batida vertical e pano-de-batida largo não se diferenciam em relação ao número de percevejos ninfas, adultos e total (ninfas + adultos) coletado. Ainda, de maneira geral, esses dois métodos de amostragem são mais eficientes que o método pano-de-batida, devido a sua maior capacidade de coleta de percevejos. Resultado semelhante foi obtido por MASSARO \& GAMUNDI (2003), que verificaram que o pano-debatida vertical coletou mais percevejos que o pano-debatida e, ainda, a diferença foi maior em espaçamentos menores. A maior extração de percevejos constatada, quando o pano é utilizado em apenas uma fileira de soja, é facilmente explicada pelo efeito do reduzido espaçamento e do maior porte das plantas. Assim, forma-se um emaranhado de massa foliar quando as plantas das duas fileiras adjacentes são curvadas e batidas sobre o pano, impedindo o total desalojamento dos percevejos para o pano. Outros trabalhos, como o de GUEDES et al. (2006), compararam o pano-de-batida e pano-de-batida vertical e verificaram maior eficiência de coleta de $\boldsymbol{P}$. guildinii do pano-de-batida vertical no espaçamento de $0,40 \mathrm{~m}$ entre linhas. Em trabalho realizado por CORRÊA-FERREIRA\& PAVÃO (2005), o pano-de-batida largo foi mais eficiente na coleta de percevejos, em relação ao pano-de-batida, confirmando o encontrado neste trabalho.

Procedimentos de amostragem adequados e que possam ser utilizados para quantificar a densidade populacional de todas as espécies de artrópodes encontrados na soja são inexistentes. Na prática, o método de amostragem a ser utilizado é determinado pela espécie a ser amostrada, pela precisão desejada, pelo custo de amostragem, pelo tempo necessário e pela reprodutibilidade de resultados (WADE et al.,
2006). Neste estudo, ficou evidenciado que há diferença entre os métodos de amostragem, em relação à capacidade de coleta de lagartas e de percevejos, e que o método de amostragem pano-de-batida vertical deve ser o preferido pela sua maior eficácia para as espécies e as idades dos insetos-praga ou para os distintos momentos da fenologia da cultura.

Considerando os resultados obtidos para lagartas e percevejos de soja e a ordem de eficácia de amostragem dos métodos, é possível inferir que o panode-batida vertical e o pano-de-batida largo, nessa ordem, são mais eficazes na amostragem de insetos-praga para a mesma área de plantas de soja amostrada. Entre os dois métodos mais eficazes, o pano-de-batida vertical foi ligeiramente mais eficiente, já que, somado a sua facilidade de uso (instalação, sacudida das plantas e contagem dos insetos), torna sua recomendação pelos órgãos de pesquisa e adoção pelos produtores mais fácil e adequado ao manejo de pragas de soja.

Desse modo, para amostrar a mesma área, neste estudo de $1 \mathrm{~m}^{2}$, com os métodos pano-de-batida vertical e pano-de-batida largo, são necessárias duas amostragens (duas batidas), enquanto que com o panode-batida apenas uma amostragem é suficiente. Quando a densidade populacional de lagartas e de percevejos está próxima do nível de controle, a eficácia do método de amostragem utilizado (pano-de-batida, pano-de-batida largo ou pano-de-batida vertical) poderá influenciar na decisão de controle, haja vista a diferente capacidade de coleta destes e a inflexibilidade do nível de controle (necessidade de fator de correção para cada método). Já em situações de alta incidência de lagartas e de percevejos, o fato de utilizar qualquer um dos três métodos estudados (pano-de-batida, panode-batida largo ou pano-de-batida vertical), provavelmente, não influenciará na decisão de controle dos insetos-praga, pois, mesmo aquele de menor capacidade de coleta, possivelmente, acusará densidade populacional acima do nível de controle. Dois aspectos desse cenário são pouco mutáveis e merecem uma discussão mais profunda. O primeiro é que a população de insetos é absoluta no instante da amostragem e, segundo, o nível de controle atualmente proposto é fixo, portanto, se os métodos fossem igualmente eficazes, a decisão de controlar emanaria igualmente de todos. No entanto, dada a distinta eficácia dos métodos, a indicação de controlar as pragas da soja pode variar para cada método.

\section{CONCLUSÃO}

Na cultura de soja, o número de lagartas coletadas por meio dos métodos de amostragem é 
decrescente na seguinte ordem: pano-de-batida vertical, pano-de-batida largo e pano-de-batida. $\mathrm{O}$ número de percevejos coletados por meio dos métodos de amostragem pano-de-batida vertical e pano-debatida largo é superior ao pano-de-batida. O pano-debatida vertical é o mais eficiente para a coleta de lagartas e de percevejos em sistemas de amostragem do Manejo Integrado de Pragas da soja.

\section{AGRADECIMENTOS}

Ao Conselho Nacional de Desenvolvimento Científico e Tecnológico (CNPq) e à Coordenação de Aperfeiçoamento de Pessoal de Nível Superior (CAPES), pelas bolsas concedidas.

\section{REFERÊNCIAS}

BELORTE, L.C. et al. Danos causados por percevejos (Hemiptera: Pentatomidae) em cinco cultivares de soja (Glycine $\max ($ L.) Merrill, 1917) no município de Araçatuba, SP. Arquivos Instituto Biológico, v.70, p.169-175, 2003. Disponível em: <http://200.144.6.109/docs/arq/V70_2/ belorte.pdf>. Acesso em: 08 mar. 2012.

BOYER, W.P.; DUMAS, B.A. Plant shaking methods for soybean insect survey in Arkansas. In: ___ Survey methods for some economic insects. USA: Dep Agric Agric Res Ser, 1969. p.92-94.

CORRÊA-FERREIRA, B.S. Suscetibilidade da soja a percevejos na fase anterior ao desenvolvimento das vagens. Pesquisa Agropecuária Brasileira, v.40, p.1067-1072, 2005. Disponível em: <http://www.scielo.br/pdf/pab/v40n11/ a03v4011.pdf >. Acesso em: 08 mar. 2012. doi: 10.1590/ S0100-204X2005001100003.

CORRÊA-FERREIRA, B.S.; AZEVEDO, J. Soybean seed damage by different species of stink bugs. Agriculture and Forest Entomology, v.4, p.145-150, 2002. Disponível em: <http://onlinelibrary.wiley.com/doi/10.1046/j.14619563.2002.00136.x/pdf >. Acesso em: 08 mar. 2012. doi: 10.1046/j.1461-9563.2002.00136.x.

CORRÊA-FERREIRA, B.S.; PAVÃO, A.L. Monitoramento de percevejos da soja: maior eficiência no uso do pano-de-batida. In: REUNIÃO DE PESQUISA DE SOJA DA REGIÃO CENTRAL DO BRASIL, 27., 2005, Londrina, PR. Resumos... Londrina: Embrapa Soja, 2005. p.152-153.

COSTA, E.C.; CORSEUIL, E. Avaliação da eficiência de cinco métodos de levantamento de artrópodes associados à cultura da soja (Glycine Max (L.) Merril). Revista do Centro de Ciências Rurais, v.1, p.81-93, 1979.

CRUZ, C.D. Programa genes: estatística experimental e matrizes. Viçosa: UFV, 2006. 285p.

DEGRANDE, P.E. et al. Avaliação de métodos para quantificar predadores de pragas do algodoeiro. Arquivo Instituto Biológico, v.70, p.291-294, 2003. Disponível em: <http:// 200.144.6.109/docs/arq/V70_3/degrande.PDF>. Acesso em: 08 mar. 2012
DREES, B.M.; RICE, M.E. The vertical beat sheet: a new device for sampling soybean insects. Journal of Economic Entomology, v.78, p.1507-1510, 1985 .

GUEDES, J.V.C. et al. Capacidade de coleta de dois métodos de amostragem de insetos-praga da soja em diferentes espaçamentos entre linhas. Ciência Rural, v.36, p.1299-1302, 2006. Disponível em: <http://www.scielo.br/pdf/cr/v36n4/ a40v36n4.pdf>. Acesso em: 08 mar. 2012. doi: 10.1590/ S0103-84782006000400040.

KNUTSON, A.E. et al. Evaluation of sampling methods and development of sample plans for estimating predator densities in cotton. Journal of Economic Entomology, v.101, p.15011509, 2008. Disponível em: <http://ddr.nal.usda.gov/bitstream/ 10113/27966/1/IND44188884.pdf>. Acesso em: 08 mar. 2012. doi: 10.1603/0022-0493(2008)101[1501:EOSMAD]2.0.CO;2.

LARA, R.I.R. et al. Amostragem, diversidade e sazonalidade de Hemerobiidae (Neuroptera) em Coffea arabica L. cv. 'Obatã' (Rubiaceae). Revista Brasileira de Entomologia, v.52, p.117-123, 2008. Disponível em: <http://www.scielo.br/pdf/ rbent/v52n1/20.pdf>. Acesso em: 08 mar. 2012. doi: 10.1590/ S0085-56262008000100020.

LOURENÇÃO, A.L. et al. Produtividade de genótipos de soja sob infestação da lagarta-da-soja e de percevejos. Neotropical Entomology, v.39, p.275-281, 2010. Disponível em: <http:/ /www.scielo.br/pdf/ne/v39n2/v39n2a20.pdf >. Acesso em: 08 mar. 2012. doi: 10.1590/S1519-566X2010000200020.

MASSARO, R.A.; GAMUNDI, J.C. Control de insectos plaga en soja: del ojímetro...jal paño vertical! - 2003. Oliveros: INTA EEA, 2003. Disponível em: <http://www.elsitioagricola.com/ articulos/massaro/Control\%20de\%20Plagas\%20en\%20Soja\%20$\% 20$ De1\%20ojimetro\% 20 al $\% 20$ panio $\% 20$ vertical $\% 20$ \%202003.asp>. Acesso em: 08 mar. 2012.

MUSSER, F. et al. Comparison of direct and indirect sampling methods for tarnished plant bug (Hemiptera: Miridae) in flowering cotton. Journal of Economic Entomology, v.100, p.19161923, 2007. Disponível em: <http://ddr.nal.usda.gov/bitstream/ 10113/11942/1/IND43994574.pdf>. Acesso em: 08 mar. 2012. doi: 10.1603/0022-0493(2007)100[1916:CODAIS]2.0.CO;2.

REUNIÃO DE PESQUISA DE SOJA DA REGIÃO SUL, 38., 2010, Cruz Alta. Indicações técnicas para a cultura da soja no Rio Grande do Sul e em Santa Catarina 2010/ 2011 e 2011/2012. Cruz Alta: Fundacep Fecotrigo, 2010. 168p.

RITCHIE, S.W. et al. How a soybean plant develops. Ames: Iowa State University of Science And Technology Cooperative Extension Service, 1982. 20 p. (Special Report, 53).

SANE, I. et al. Efficiency of conventional sampling methods for determining arthropod densities in close-row soybeans. Journal Agricultural and Urban Entomology, v.16, p.6584, 1999. Disponível em: <http://scentsoc.org/Volumes/JAUE/ v16/65.pdf>. Acesso em: 08 mar. 2012.

SHEPARD, M. et al. A comparison of three sampling methods for arthopods in soybeans. Environmental Entomology, v.3, p.227-232, 1974

WADE, M.R. et al. Temporal variation in arthropod sampling effectiveness: the case for using the beat sheet method in cotton. Entomologia Experimentalis et Applicata, v.120, p.139153, 2006. Disponível em: <http://onlinelibrary.wiley.com/ doi/10.1111/j.1570-7458.2006.00439.x/pdf>. Acesso em: 08 mar. 2012. doi: 10.1111/j.1570-7458.2006.00439.x. 